\title{
Analysis of Vibration Characteristics of PD Control Active Magnetic Bearing and Cracked Rotor System
}

\author{
Z. Zhixian*a, J. Bolonga, W. Jiayuana, L. Yixina, Z. Changsheng ${ }^{\mathrm{b}}$ \\ ${ }^{a}$ College of Mechanical and Control Engineering, Guilin University of Technology, Guilin, China \\ ${ }^{b}$ College of Electrical Engineering, Zhejiang University, Hangzhou, China
}

\section{PAPER INFO}

\section{Paperhistory:}

Received 13 December 2018

Received in revised form 29 January 2019

Accepted 07 March 2019

\section{Keywords}

Active Magnetic Bearings

PD Control

Cracked Rotor

Finite Element Methods

\section{$A B S T R$ R A C T}

Crack fault of rot or is one of the most prominent problems faced by magnetic bearing rotor system. In order to improve the safety performance of this kind of machinery, it is necessary to research the vibration characteristics of magnetic bearing cracked rotor system. In this paper, the st iffness model of the crack shaft element was established by the strain energy release rate (SERR) theory. The mathematical model of PD controller of AMBs cracked rotor system is based on the finite element method. The vibration characteristics of PD controller of AMBs rotor system were examined in the test rig under crack depth of rotor. The spectrum of vibration characteristics were detected in the AMBs cracked rotor system. The results of experiments showed that the $2 \times$ and $3 \times$ harmonic components can be used for fault diagnosis of crack fault of AMBs rotor systems under PD controller of AMB.

doi: $10.5829 /$ ije.2019.32.04a.18

\section{INTRODUCTION}

Active magnetic bearings are becoming the preferred method for the bearing of high speed and ultra-high speed rotary machines. Compared with medium and low-speed rotors, high speed and ultra-high speed rotors may generate cracks more easily due to high rate cyclic stress. If crack is not detected on time, which would lead to rotor failure or even an accident.

There has been a lot of research literatures on the monitoring, detection, diagnosis and other dynamics of rotor cracks since 1950s [1, 2]. Most of these researchs mainly focus on the following four aspects such as the calculation of crack stiffness [3], the mathematical model of cracked rotor [4], the analysis of the dynamic characteristics of vibration [5-8], the identification of crack faults in traditional bearings (rolling bearing, oil film sliding bearing) and rotor system[1-4]. Additionally, there is very limited literature on the fault of a crack rotor supported by active magnetic bearings [9-14]. The equation of motion for Jeffcott cracked-rotor was established by Mani et al. [10] in which a traditional bearing is placed at both ends of the shaft and electromagnetic bearing in the middle as force actuators, and the harmonic component of vibration response of the cracked rotor was identified based on the variability of the electromagnetic excitation force on the experimental bench [9-11]. The reported literature [9-11] show that it is feasible to use the excitation response signal of the electromagnetic bearing is feasible to monitor and detect crack faults on the rotor system. Zhou and Friswell [12] established a simulation model based on Mani's theory, and the simulation results show that the vibration characteristics of the cracked rotor can be made more obvious by increasing load or the electromagnetic force of the electromagnetic bearing. But increasing the electromagnetic force of the electromagnetic bearing, or the rotor crack depth will make systematic crack fault identification more difficult. Zhu and Zhong [13-15] analyzed the dynamic characteristics of a cracked rotor system with active feedback control and found that the characteristics of such a rotor system are much more complex than those of traditional bearings and cracked rotor system. 
Nonetheless, there are many problems associated with active magnetic bearings and cracked rotor system that are yet to be solved, such as including the impact of cracks on the stability of active magnetic bearings' control system, and the dynamic characteristics of active magnetic bearing and cracked rotor system, etc. It is necessary to further study on the dynamic characteristics of cracked rotor in order to realize the cracked fault of early identification and diagnosis in an active magnetic bearings and rotor system.

In this paper, the finite element model of PD control AMBs and cracked rotor system is established. The vibration characteristics of AMBs and cracked rotor systems are examined by simulation. It is also analyzed that the vibration characteristics of PD control AMBs and flexible rotor under certain crack depths or AMBs' equivalent stiffness, and the results show that crack faults in rotor systems of AMBs can be identified by monitoring vibration signals.

\section{MODEL OF AMBS AND CRACKED ROTOR SYSTEM}

\section{1. Current Coefficient and Displacement} Coefficient of AMB For the AMBs and rotor system shown in Figure 1, mass discs of $m$ are mounted on the middle of the flexible shaft with a length $l$ and a radius $R$, while an AMB supports each end of the shaft. There is also a trans verse crack near the intermediate disc with a depth $a$ on the axis.

By neglecting the effects of magnetic saturation, hysteresis, magnetic flux leakage and eddy current loss, the linear electromagnetic force of the radial active electromagnetic bearing is obtained stated as follows [14-16]:

$F_{A M B}=\left[\frac{F_{x}}{F_{y}}\right]=\left[\begin{array}{cc}k_{s x} & 0 \\ 0 & k_{s y}\end{array}\right]\left[\begin{array}{l}x \\ y\end{array}\right]+\left[\begin{array}{cc}k_{i x} & 0 \\ 0 & k_{i y}\end{array}\right]\left[\begin{array}{l}i_{x} \\ i_{y}\end{array}\right]$

where, $k_{s x}$ and $k_{s y}$ are the displacement coefficients, $k_{i x}$ and $k_{i y}$ are the current coefficients of the AMB. $x$ and $y$ are the air gap displacements of the AMB. and $i_{x}$ and $i_{y}$ are the control currents of $\mathrm{x}$ and $\mathrm{y}$ directions, respectively. For two pairs of the radial electromagnet of AMB, the calculations of displacement coefficients and the current coefficients of AMB are as follows [14, 16]:

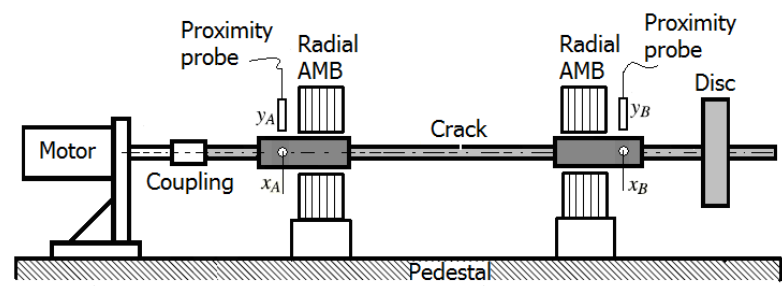

Figure 1. Structure of an AMB-rotor system. $k_{s x}=\mu_{0} A N^{2} i_{0 x}^{2} \cos ^{2}(\pi / 8) / s^{3}$

$k_{s y}=\mu_{0} A N^{2} i_{0 y}^{2} \cos ^{2}(\pi / 8) / s^{3}$

$k_{i x}=-\mu_{0} A N^{2} i_{0 x}^{2} \cos ^{2}(\pi / 8) / s^{2}$

$k_{i y}=-\mu_{0} A N^{2} i_{0 y}^{2} \cos ^{2}(\pi / 8) / s^{2}$

where, $s$ is the nominal air gap; $i_{0 x}$ and $i_{0 y}$ are the bias current of the magnetic bearing in the $x$ and $y$ directions, respectively. $\mu_{0}=4 \pi \times 10^{-7} \mathrm{H} / \mathrm{m}$ is the air permeability. $N$ is the number of turns of the coil; and $A$ is the crosssectional area of the air gap.

\section{2. Model of PD Controlled AMBs and Rotor} System The kinematic equation of the rotor system in a fixed rectangular coordinate system is established by the finite element method [13, 14].

$M \ddot{U}+(C+\omega G) \dot{U}+K U=F_{A M B}+Q+W$

where, $M$ is the mass matrix including the rotating shaft and the rigid disc, $G$ is the gyro matrix including the rotating shaft and the rigid disc, $C$ is the damping matrix, $K$ is the stiffness matrix of the rotating shaft, $U$ is the displacement vector of each node, $Q$ is the gravitational vector, and $W$ is the unbalanced force vector at the disc.

From formula (1), where:

$K(\mathrm{~s})=\left[\begin{array}{cc}k_{s x} & 0 \\ 0 & k_{s y}\end{array}\right]$

$K(i)=\left[\begin{array}{cc}k_{i x} & 0 \\ 0 & k_{i y}\end{array}\right]$

From formula (1), (3), (4) and (5), the state equation of PD controlled AMBs-rotor systemis as follows:

$U=\left[\begin{array}{cc}0 & I \\ -M^{-1}[K-K(s)] & -M^{-1}[C+G \omega]\end{array}\right] \dot{U}+$

$\left[\begin{array}{c}0 \\ M^{-1} K(i)\end{array}\right] I(s)+M^{-1}[\mathrm{Q}+\mathrm{W}]$

$I(s)=\left(k_{p}+k_{d} s\right) U$

where, $k_{\mathrm{p}}$ and $k_{\mathrm{d}}$ are the PD controller of AMBs parameters.

\section{3. Stiffness Model of Cracked Rotor}

When cracked rotor rotates, the crack will open and close periodically in one rotation cycle under the weight of the shaft, a process referred to as "breathing". As a result, the stiffnes s matrix $K(\mathrm{t})$ of the cracked rotor is nonlinear [13, 17]. The actual model of a "breathing" crack is very complex but there are several crack models at present, such as Gasch's opening and closing crack model, cosine wave model of Mayes and Davies proposing, and the crack model established by Gao and Zhu [14]. Dimarogonas proposed the strain energy release factor (SERR) crack model, which is based on the stress intensity factor and the strain energy density function (SEDF) in fracture mechanics [1]. Dimarogonas's SERR crack model clearly reveals the impact of the regular opening and closing of the crack on rotor stiffness. 
However, the calculation process of solving the generated equation of motion of the cracked rotor is complex and not suitable for engineering practice [18]. In this paper, the model of cracked rotor is proposed by Papadopoulos and Dimarogonas [1], which can reveal changes in stiffness of the cracked rotor better, to create a crack model that can help in solving the equation of the rotor motion simply.

As shown in Figures 2 and 3, both axial and shear forces are neglected, the radius is $R$ and the $l$ is the length from one end to center of the axis, where there is a transverse crack with a depth $a$. The opening and closing of the crack is shown in Figure 3, while the stiffness of the shaft unit is as follows [15]:

$\left[K_{c}\right]=\left[K_{0}\right]+\left[K_{1}\right] \cos (\omega t)$

$+\left[K_{2}\right] \cos (2 \omega t)+\left[K_{3}\right] \cos (3 \omega t)+\left[K_{4}\right] \cos (4 \omega t)$ where,

$\left[K_{0}\right]=\frac{1}{16}\left\{5\left[K_{O P}\right]+5\left[K_{U C}\right]+6\left[K_{H C}\right]\right\}$

$\left[K_{1}\right]=\frac{9}{16}\left\{\left[K_{U C}\right]-\left[K_{O P}\right]\right\}$

$\left[K_{2}\right]=\frac{1}{4}\left\{\left[K_{O P}\right]+\left[K_{U C}\right]-2\left[K_{H C}\right]\right\}$

$\left[K_{3}\right]=\frac{1}{16}\left\{\left[K_{O P}\right]-\left[K_{U C}\right]\right\}$

$\left[K_{4}\right]=\frac{1}{14}\left\{-\left[K_{O P}\right]-5\left[K_{U C}\right]+2\left[K_{H C}\right]\right\}$

In the formula (8)-(13), the stiffness matrix of the shaft element is: $K_{O P}$, when the crack is fully open; $K_{U C}$, when the crack is fully closed, and $K_{H C}$, when the crack is half open. $K_{O P}$ and $K_{U C}$ were calculated by using Dimarogonas's SERR method and the local flexibility matrix produced by the crack axis at four degrees of freedom $[1,2]$.

$\left[C_{c r}\right]=\left[\begin{array}{ccrl}\bar{c}_{11} & 0 & 0 & 0 \\ 0 & \bar{c}_{22} & 0 & 0 \\ 0 & 0 & \bar{c}_{33} & \bar{c}_{34} \\ 0 & 0 & \bar{c}_{43} & \bar{c}_{44}\end{array}\right]$

The total flexibility of the cracked shaft element is as follows:

$\left[C_{g}\right]=\left[G_{1}\right]\left[G_{c r}\right]\left[G_{2}\right]+\left[C_{u c}\right]$

where,

$$
\begin{aligned}
& {\left[G_{1}\right]=\operatorname{diag}\left[\begin{array}{llll}
1 & 1 & \frac{l}{2} & \frac{l}{2}
\end{array}\right]} \\
& {\left[G_{2}\right]=\operatorname{diag}\left[\begin{array}{llll}
1 & 1 & \frac{l}{4} & \frac{l}{4}
\end{array}\right]} \\
& {\left[C_{u c}\right]=\operatorname{diag}\left[\begin{array}{llll}
\frac{l}{4 A G} & \frac{l}{4 A G} & \frac{l^{3}}{48 E I} & \frac{l^{3}}{48 E I}
\end{array}\right]}
\end{aligned}
$$

In the above formula, $C_{g}$ is the total flexibility matrix of the cracked axis element; $C_{c r}$ is the local flexibility matrix of the cracked axis element; $C_{u c}$ is the flexibility matrix of the axis element when no crack exists. By using the inverse matrix of each softness matrix, the stiffness matrix $K_{O P}, K_{U C}, K_{H c}$ are calculated, and the stiffness matrix $K_{c}$ of cracked shaft element are obtained from formula (8).

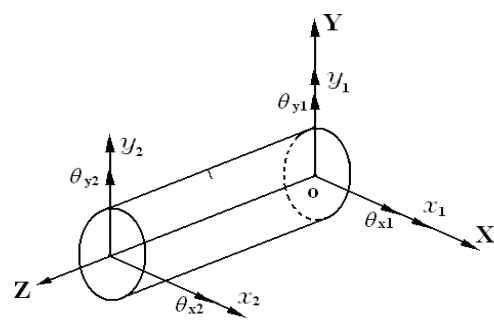

Figure 2. Cracked shaft element

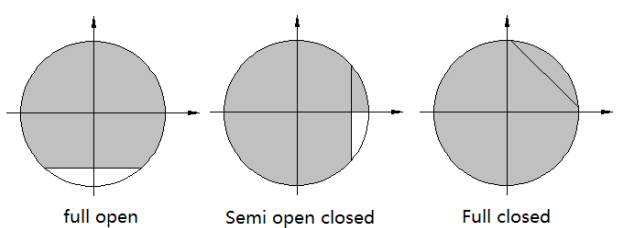

Figure 3. Crack model

$\left[K_{o p}\right]=\left[C_{g}\right]_{o p}^{-1},\left[K_{U C}\right]=\left[C_{g}\right]_{u c}^{-1},\left[K_{H C}\right]=\left[C_{g}\right]_{h c}^{-1}$

In formula (18), $E, G, I, l$ and $R$ are the elastic modulus, shear modulus, moment of inertia, length and radius of the axis, respectively.

\section{4. Equation of Motion for AMB-Cracked Rotor} System In the $n$ axis units of the shaft, the $j$-axis element is the crack axis. The equation of motion of the crack rotor system is as follows [13-15]:

$$
\begin{array}{r}
U=\left[\begin{array}{cc}
0 & I \\
-M^{-1}\left[K+K_{c}-K(s)\right] & -M^{-1}[C+G \omega]
\end{array}\right] \dot{U} \\
+\left[\begin{array}{c}
0 \\
M^{-1} K(i)
\end{array}\right] I(s)+M^{-1}[Q+W]
\end{array}
$$

where, $K_{c}$ is the stiffness matrix of crack section of $j$ element in the shaft.

\section{SIMULATION AND EXPERIMENTAL ANALYSIS}

\section{1. Analysis of Simulation}

The rotor system is shown in Figure 1, where axis length $l=800 \mathrm{~mm}$, axis diameter $R=10 \mathrm{~mm}$, and the rotor is discretized into 16 beam elements. The diameter of the disc on the shaft $D=$ $200 \mathrm{~mm}$ and disc thickness $h=25 \mathrm{~mm}$. The unbalance of the disc is $m \cdot e=100 \mathrm{~g} \cdot \mathrm{mm}$ and the initial angle $\varphi=0$. The electromagnetic coil has a total of 110 turns and the cross-sectionalarea of air gap is $0.0013 \mathrm{~m}^{2}$, while that of the nominal air gap is $0.2 \times 10^{-3} \mathrm{~m}^{2}$.

As shown in Figure 4, the rotor is divided into finite elements, and the crack is located in the 8th element. The equation of motion of the rotor can be derived from formula (20). The cracked rotor systemis a periodic time varying nonlinear system due to the opening and closing of the crack. The Runge-Kutta method are used to analyzing the imbalance response of a cracked rotor systemin this paper. 


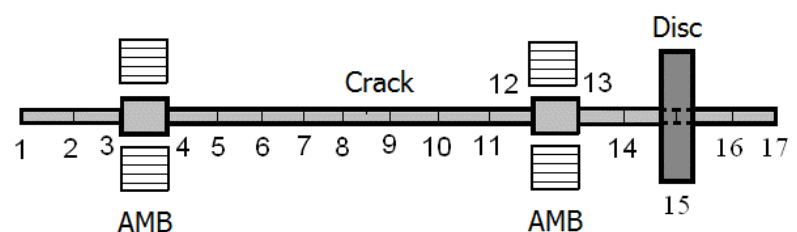

Figure 4. FEM of rotor

Figure 5-(a), (b), (c) and (d) illustrate the orbit of the cracked rotor system and the vibration spectrum of the rotor in the y direction (vertical direction) under different bias current conditions of AMBs' electromagnet. It can be seen that when the bias current of the electromagnet is $1 \mathrm{~A}$, the harmonic components of $2 x$ and $3 x$ are not obvious in the vibration spectrum of the cracked rotor. However, when the bias current of the electromagnetic of bearing is $2 \mathrm{~A}$, the magnitudes of $2 x$ and $3 x$ harmonic components increased obviously in the vibration spectrum of the cracked rotor.

From Figure 5, it can be seen that the harmonic component of AMBs-cracked rotor systemcan be used as the diagnostic index of the rotor crack with certain equivalent stiffness conditions of AMBs. But when the equivalent stiffness of AMBs is small, the PD controller of AMBs can suppress the vibration characteristics of rotor. So it is not useful to diagnosis of the rotor crack fault using the harmonic components of rotor's vibration when the bias current of AMB is smaller.
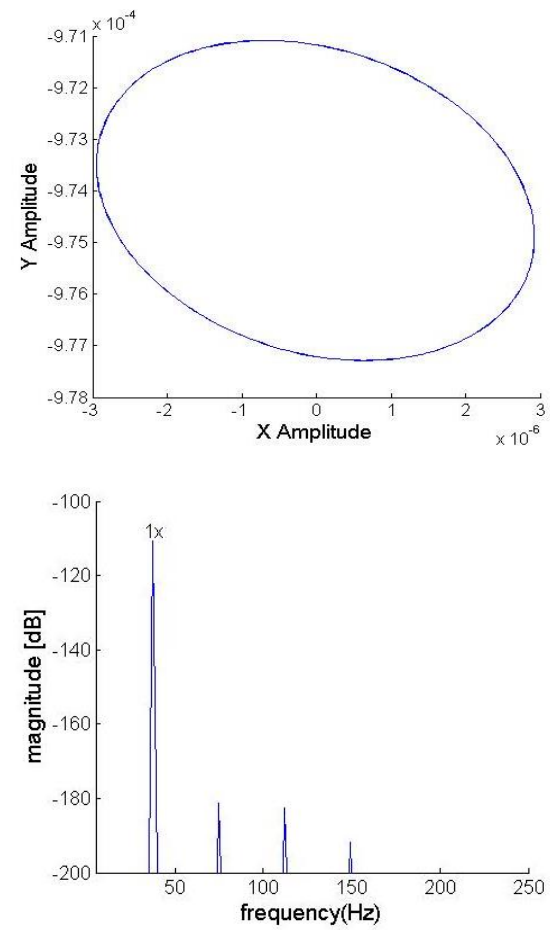
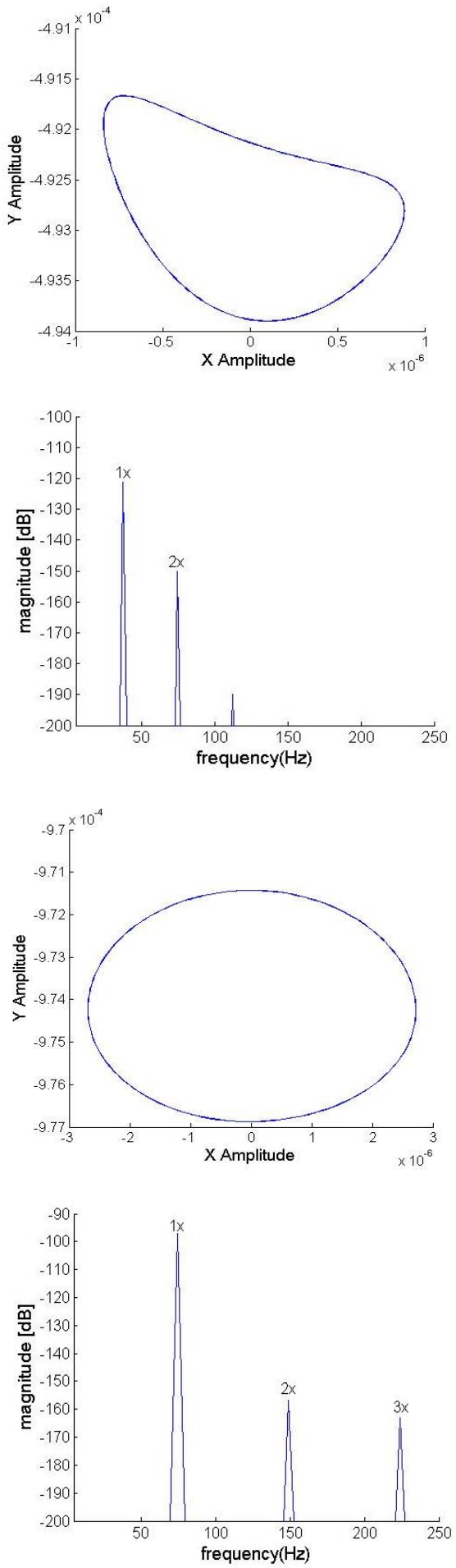

Figure 5. Orbit of the cracked rotor system and the vibration spectrum of the rotor in vertical direction under bias current and rotation speed of AMBs; (a) The bias current $i_{0}=1 \mathrm{~A}$, relative depth of the crack $a=0.4 R$, rotation speed of the rotor $n=$ 2400rpm; (b) The bias current $i_{0}=2 \mathrm{~A}$, relative depth of the crack $a=0.4 R$, rotation speed of the rotor $n=2400 \mathrm{rpm}$; (c) The bias current $i_{0}=2 \mathrm{~A}$, relative depth of the crack $a=0.4 R$, rotation speed of the rotor $n=4500 \mathrm{rpm}$. 


\section{2. Experiments and Analysis The experimental} platform of AMB and flexible rotor system is shown in Figure 6. And main parameters of the AMBs are given in Table 1. The vibration of the shaft was detected by four eddy current displacement sensors. Dspace1006 was chosen as the controller, while Dspace 2003 was used as the $\mathrm{A} / \mathrm{D}$ and $\mathrm{D} / \mathrm{A}$ modules. The crack was realized by line cutting the shaft to obtain a slit with a depth of $4 \mathrm{~mm}$ and a width of $0.15 \mathrm{~mm}$. Then $0.15 \mathrm{~mm}$ thick piece of copper was embedded in the slit, and one of its sides bonded to the slit by a high-strength metallic adhesive. The crack obtained by this method as well as its position on the shaft is shown in Figure 7.

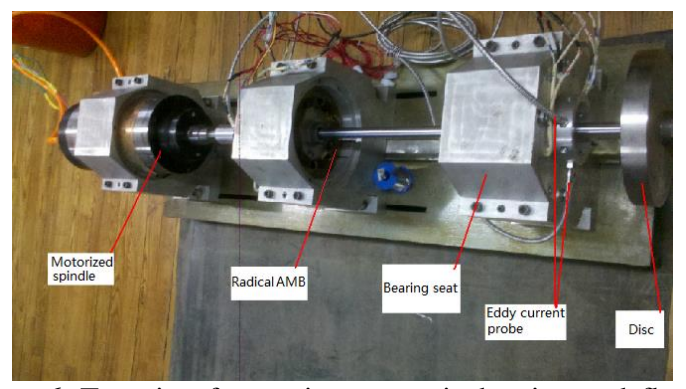

Figure 6. Test rig of an active magnetic bearing and flexible rotor system.

TABLE 1. AMB's main parameters

\begin{tabular}{lc}
\hline Parameters & Values \\
\hline Inner diameter of AMB's stator & $95.6 \mathrm{~mm}$ \\
Outer diameter of AMB's stator & $170 \mathrm{~mm}$ \\
Inner diameter of AMB's rotor & $20 \mathrm{~mm}$ \\
Outer diameter of AMB's rotor & $95 \mathrm{~mm}$ \\
Area magnetic pole & $1147.12 \mathrm{~mm}^{2}$ \\
Coil turns & 110 \\
Air gap & $0.3 \mathrm{~mm}$ \\
Angle of magnetic pole & $22.5^{\circ}$ \\
Coil resistance & $2.5 \Omega$ \\
Saturation magnetic dense & $1.2 \mathrm{~T}$ \\
Force-current coefficient & $716.2 \mathrm{~N} / \mathrm{A}$ \\
Force-displacement coefficient & $2.205 \mathrm{kN} / \mathrm{mm}$ \\
\hline
\end{tabular}

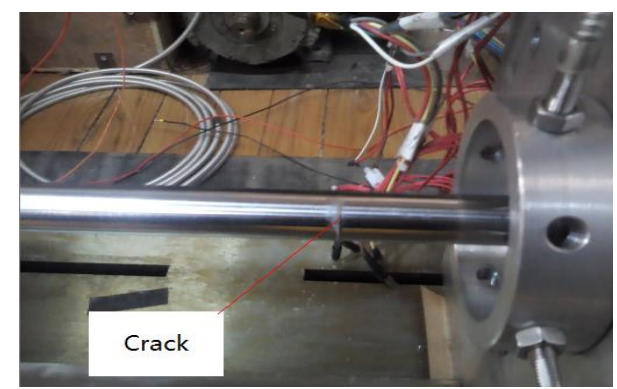

Figure 7. The position of the crack on the shaft.
Figure 8 shows the vibration of the cracked rotor system at a rotational speed of $4500 \mathrm{rpm}$, and the vibration spectrum of rotor in the y-direction (vertical). By looking at the vibration signal of the cracked rotor system, it can be seen that the amplitude of $2 \times$ and $3 \times$ harmonic components is obvious. Hence, this experimental phenomenon confirms that the simulation results are correct.
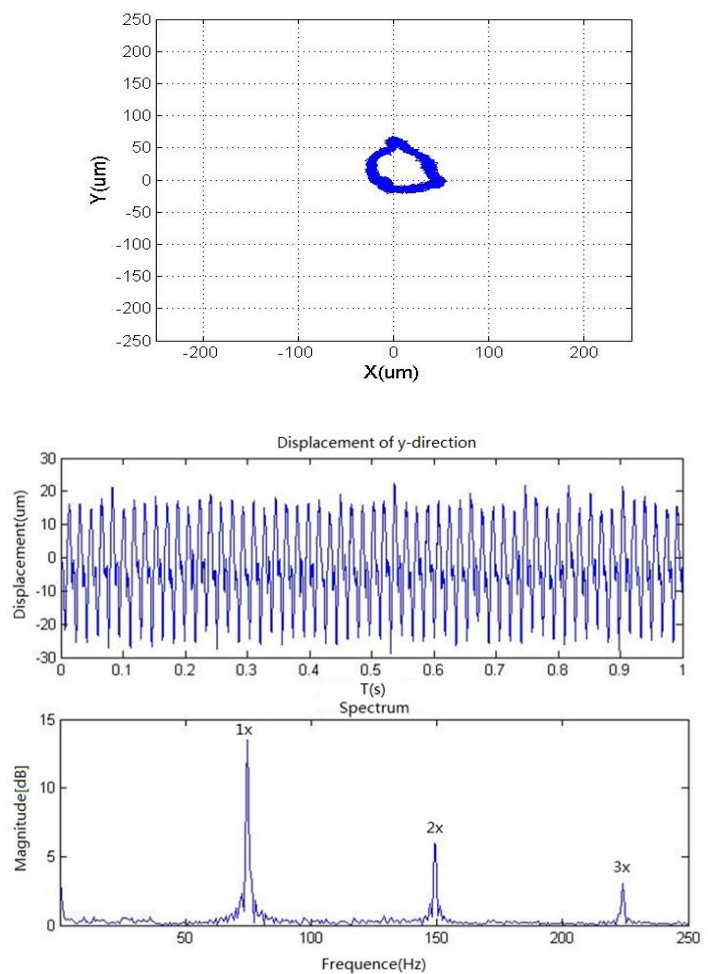

Figure 8. Orbit of the AMBs-cracked rotor system and vibration characteristics at speed of the rotor $n=4500 \mathrm{rpm}$; (a) Orbit of cracked rotor vibration at speed of the rotor $n$ $=4500 \mathrm{rpm}$; (b) The cracked rotory-direction vibration and FFT spectrum.

\section{CONCLUSION}

The following conclusions can be drawn from the simulation and experimental analysis of PD control AMBs and cracked rotor systems.

The dynamic characteristics of the PD control AMBs and cracked rotor system are more complicated than those of the traditional bearings and cracked rotor system. Additionally, the vibration characteristics of a cracked rotor system are influenced by the equivalent stiffness of AMBs and the parameters of the controller as well.

Under stiffness of the electromagnetic bearings, the vibration amplitude of multiplier component such as the $2 x$ and $3 \times$ harmonics in the AMBs and cracked rotor systemcan be used as the crack faults diagnostic index of AMBs and rotor system. 


\section{ACKNOWLEDGMENTS}

This work was sponsored by the National Natural Science Foundation of China $(51565009,11632015$, 51477155), the Natural Science Foundation of Guangxi Province (2015GXNSFAA139272).

\section{REFERENCE}

1. Papadopoulos, C. A., "The strain energy release approach for modeling cracks in rotors: A state of the art review", Mechanical Systems and Signal Processing, Vol. 22, No. 4, (2008), 763-789.

2. Dimarogonas, A. D., "Vibration of cracked structures: A state of the art review", Engineering Fracture Mechanics, Vol. 55, No. 5, (1996), 831-857.

3. Peng, Z. K., Lang, Z. Q., Meng, G., Chu, F. L., "The Effects of Crack on the Transmission Matrix of Rotor Systems", Shock and Vibration, Vol. 18, No. 1-2, (2010), 91-103.

4. Han, D. J., "Vibration analysis of periodically time-varying rotor system with transverse crack", Mechanical Systems and Signal Processing, Vol. 21, No. 7, (2007), 2857-2879.

5. Toloei, A., Aghamirbaha, E., and Zarchi, M., "Mathematical Model and Vibration Analysis of Aircraft with Active Landing Gear System using Linear Quadratic Regulator Technique", International Journal of Engineering - Transactions B: Applications, Vol. 29, No. 2,(2016), 137-144.

6. Yuan, M., "Compact and Efficient Active Vibro-acoustic Control of a Smart Plate Structure", International Journal of Engineering - Transactions B: Applications, Vol. 29, No. 8, (2016), 1068-1074.

7. Attaran, B., Zarchi, M., and Toloei, A. R., "Optimized Fuzzy Logic for Nonlinear Vibration Control of Aircraft Semi-active Shock Absorber with Input Constraint (TECHNICAL NOTE)", International Journal of Engineering - Transaction C: Aspects, Vol. 29, No. 9, (2016), 1300-1306.

8. Guo, D. and Peng, Z. K., "Vibration analysis of a cracked rotor using Hilbert-Huang transform”, Mechanical Systems and Signal Processing, Vol. 21, No. 8, (2007), 3030-3041.
9. Kasarda M.M., Bash T.T., Quinn D.D., Mani G.G., Inman D.D., and Kirk R.G., "A New Approach for Health Monitoring and Detection of Shaft Crack Using an Active Magnetic Actuator During Steady-State Rotor Operation", In International Gas T urbine Institute, ASME Turbo Expo 2007: Power for Land, Sea, and Air, Volume 5, (2007), 879-883.

10. Mani, G., Quinn, D. D., and Kasarda, M., "Active health monitoring in a rotating cracked shaft using active magnetic bearings as force actuators", Journal of Sound and Vibration, Vol. 294, No. 3, (2006), 454-465.

11. Quinn, D., Mani, G., Kasarda, M. E. F., Bash, T., Inman, D. and Kirk, R. G., "Damage Detection of a Rotating Cracked Shaft Using an Active Magnetic Bearing as a Force ActuatorAnalysis and Experimental Verification", IEEE/ASME Transactions on Mechatronics, Vol. 10, No. 6, (2005), 640-647.

12. Zhou, C., Friswell, M.I., and Li, J., "Condition Monitoring of Cracked Shaft using Active Magnetic Bearings," In Challenges of Power Engineering and Environment, (2007), 494-504

13. Zhu, C., Robb, D. A., and Ewins, D. J., "The dynamics of a cracked rotor with an active magnetic bearing", Journal of Sound and Vibration, Vol. 265, No.3, (2003), 469-487.

14. Zhu C. S. and Zhong Z.X., "The dynamics of a cracked rotor with active magnetic dampers", Journal of Vibration Engineering, Vol. 23, No. 3, (2010), 298-304.

15. Zhong, Z., and Zhu, C., "Effects of Active Magnetic Bearing Controller on Fault Characteristics of Jeffcott Cracked Rotor", Proceedings of the CSEE (Chinese Society of Electrical Engineering), Vol. 32, No. 5, (2012), 105-110.

16. Zhixiana, Z., Changshengb, Z., and Lieping, Z., " $\mathrm{H}^{\infty}$ Robust Controller Design and Experimental Analysis of Active Magnetic Bearings with Flexible Rotor System", International Joumal of Engineering - Transaction B: Applications, Vol. 28, No. 8, (2015), 1233-1240.

17. Zou, J. and Chen, J., "A comparative study on time-frequency feature of cracked rotor by Wigner-Ville distribution and wavelet transform", Journal of Sound and Vibration, Vol. 276, No. 1-2, (2004), 1-11.

18. El Arem, S. and Ben Zid, M., "On a systematic approach for cracked rotating shaft study: breathing mechanism, dynamics and instability", Nonlinear Dynamics, Vol. 88, No. 3,(2017), 2123 2138 .

\section{Analysis of Vibration Characteristics of PD Control Active Magnetic Bearing and Cracked Rotor System \\ RESEARCH NOTE}

\section{Z. Zhixiana, J. Bolonga, W. Jiayuana, L. Yixina, Z. Changshengb \\ a College of Mechanical and Control Engineering, Guilin University of Technology, Guilin, China ${ }^{b}$ College of Electrical Engineering, Zhejiang University, Hangzhou, China}

\section{$P A P E R I N F O$}

\section{Paperhistory:}

Received 13 December 2018

Received in revised form 29 January 2019

Accepted 07 March 2019

\section{Keywords}

Active Magnetic Bearings

PD Control

Cracked Rotor

Finite Element Methods
حكيده

$$
\begin{aligned}
& \text { خطاى كرك روتور يكى از مهمتر ين مشكلات مواجهه با سيستم روتور تحمل مغناطيسى است. به منظور بهبود عملكرد ايمنى }
\end{aligned}
$$

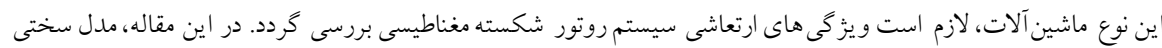

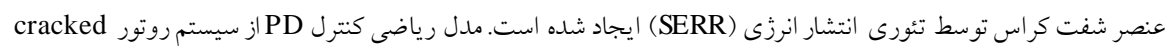

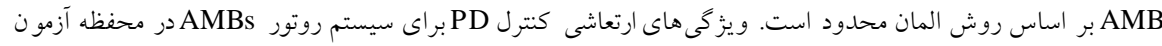

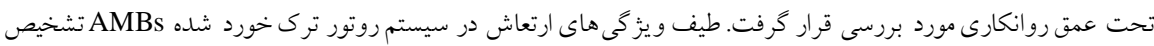

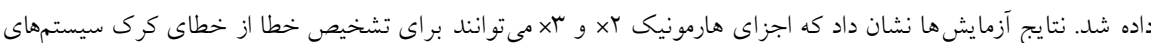

$$
\begin{aligned}
& \text { روتور AMB تحت كنترل PD براى AMB استفاده شوند. }
\end{aligned}
$$

doi: $10.5829 /$ ije.2019.32.04a.18 